\title{
MELANOCITOMA DÉRMICO FIBROSO EM BOVINO: RELATO DE CASO
}

\author{
Alesson Rodrigo Bueno Debas \\ Ana Claudia Machinski Rangel de Abreu ${ }^{1}$ \\ Alan José Ferreira \\ Liv Cristina Miara \\ Jair Rodini Engracia Filho ${ }^{1}$ \\ Rudiger Daniel Ollhoff
}

DEBAS, A. R. B.; ABREU, A. M. R. de; FERREIRA, A. J.; MIARA, L. C.; ENGRACIA FILHO, J. R.; OLLHOFF, R. D. Melanocitmoa dérmico fibroso em bovino: relato de caso. Arq. Ciênc. Vet. Zool. UNIPAR, Umuarama, v. 19, n. 1, p. 53-56, jan./mar. 2016.

RESUMO: Melanomas e melanocitomas são neoplasias de melanoblastos e melanócitos. Neoplasias melanocíticas raramente são observadas em bovinos sendo frequentemente confundidas com outros aumentos de volume ou neoplasias, apresentando comportamento predominantemente benigno. É relatado um caso de melanocitoma em uma novilha da raça Jersey de oito meses de idade, descrevendo-se seu aspecto macro e microscópico. A neoplasia foi integralmente retirada por meio cirúrgico sem complicações ou recidivas até o momento. Ressalta-se a importância para este distúrbio, principalmente para o seu diagnóstico diferencial e a resolução relativamente descomplicada para o médico veterinário.

PALAVRAS-CHAVE: Bovino. Melanocitoma. Melanoma. Neoplasias.

\section{FIBROUS SKIN MELANOCITOME IN CATTLE: A CASE REPORT}

\begin{abstract}
Melanoma and meloanocitome are melanoblast and melanocyte tumors. Melanocytic neoplasms are rarely observed in cattle and can be confused with other volume increases or neoplasms. Bovine melanoma is predominantly benign. One case of melanocitome in an 8-month old Jersey heifer is reported, describing their macro- and microscopic appearance. The tumor was completely removed by surgical means without complications. The importance of this disorder must be emphasized, especially for the differential diagnosis and the relatively uncomplicated resolution to the veterinarian. KEYWORDS: Cattle. Melanocitome. Melanoma. Neoplasia.
\end{abstract}

\section{MELANOCITOMA DÉRMICO FIBROSO EN BOVINO: RELATO DE CASO}

RESUMEN: Melanomas y melanocitomas son neoplasias de melanoblastos y melanocitos. Neoplasias melanocíticas son raramente observadas en bovino, a menudo se confunde con otros aumentos de volumen o neoplasias, presentando comportamiento predominantemente benigno. Es relatado un caso de malenocitoma en una novilla de la raza Jersey con ocho meses de edad, describiéndose su aspecto macro y microscópico. La neoplasia fue extirpada completamente por medio quirúrgico sin complicaciones o recidivas hasta el momento. Se resalta la importancia para este disturbio, especialmente para su diagnóstico diferencial y la resolución relativamente poco complicada para el médico veterinario.

PALABRAS CLAVE: Bovino. Melanocitoma. Melanoma. Neoplasias.

Introdução

Melanoma e melanocitoma são neoplasias de células produtora de melanina (melanoblastos e melanócitos) (TEIXEIRA, 1997). Os melanoblastos têm origem embriológica na crista neural, um derivado do neuroectoderma. Apesar das neoplasias de células produtoras de melanina serem comumente encontrados na pele, estas podem se originar em qualquer outro tecido que tenha origem embrionária semelhante (BABA; CÂTOI, 2007).

As neoplasias melanocíticas raramente são observadas em bovinos (GARNA-AVIÑA et al., 1981; GOURREAU et al., 1995; SMITH; GOLDSCHMIDT; MCMANUS, 2002) representando menos de $2 \%$ dos relatados nessa espécie. No entanto, quando consideradas apenas as neoplasias de pele e subcutâneo, os melanomas são responsáveis por 17 a $24 \%$ das neoplasias neste órgão (YERUHAN; PERL; ORGAD,
1999). As neoplasias melanocíticas são mais comuns em bovinos jovens, observadas principalmente entre dois meses e dois anos de idade (MILLER, 1995), podendo ter origem congênita (SIVADAS et al., 1971; MILLER et al., 1995; YERUHAN; PERL; ORGAD, 1999), não possuem predileção sexual e geralmente são constituídos de massa grande e benigna (SMITH; GOLDSCHMIDT; MCMANUS, 2002). Afetam predominantemente bovinos de pele vermelha, cinza ou preta (MILLER et al., 1995). No homem, cerca de $85 \%$ dos melanomas malignos originam-se na pele e constituem $5 \%$ de todas as neoplasias deste órgão sendo a incidência global crescente nas últimas décadas (PARKIN et al., 2005).

\section{Relato de caso}

Foi encaminhada à Unidade Hospitalar de Animais de Fazenda e Equinos da Fazenda Experimental Gralha Azul 
da Pontifícia Universidade Católica do Paraná (PUCPR), um bovino fêmea, da raça Jersey, de oito meses de idade, pesando $150 \mathrm{~kg}$ com escore de condição corporal "três" (escore variando de um a cinco), proveniente de uma propriedade no município de Fazenda Rio Grande - PR, sendo a queixa principal do proprietário um aumento de volume na região cervical. A novilha fazia parte de um rebanho de cinco animais, os quais não apresentavam os mesmos sinais, e alimentavam-se de pastagem nativa (Paspalum sp. e Brachiaria sp.) e alguma suplementação com grãos.

A novilha, atenta e em estação durante toda a anamnese e o exame físico, mostrou na inspeção da pele um aumento de volume, com tamanho e formato aproximado de um ovo de galinha, na região média da barbela cervical (Figura 1). Segundo relato do proprietário, o aumento de volume era progressivo e lento por pelo menos seis meses. Uma tentativa anterior de tratamento foi realizada pelo próprio proprietário supondo que se tratava de uma larva de Dermatobia hominis abscedada. Nessa realizou uma incisão no local com objeto perfurocortante, o qual não evidenciou nenhum conteúdo líquido-purulento e tão pouco resultado terapêutico. Na palpação, a tumoração possuía consistência firme, com nenhuma mobilidade em relação à pele que a recobria. A pele sobre a massa não se apresentava ulcerada ou alterada. O restante do pelame, a untuosidade, a espessura, a elasticidade e a temperatura da pele encontravam-se dentro dos padrões para a espécie. Pequenos papilomas verrucoides de aproximadamente um centímetro de diâmetro em pálpebra superior esquerda, comissura ocular inferior direita e no membro torácico direito foram encontrados. Os linfonodos palpáveis, em especial o pré-escapular, não demonstravam alterações (DIRKSEN et al., 1993).

Durante toda a manipulação, a novilha não demonstrou nenhuma reação dolorosa. Procedeu-se na sequência o restante do exame físico. As grandes funções avaliadas foram: frequências cardíaca, 90 bpm, respiratória, $30 \mathrm{mpm}$, ruminal, dois movimentos completos e bem audíveis em dois minutos, temperatura retal de $38,7{ }^{\circ} \mathrm{C}$ e coloração das mucosas rósea. Ressalta-se que a auscultação fonendoscópica pulmonar não demonstrou ruídos anormais, aumento de sons ou silêncio pulmonar em toda a sua extensão, o que está de acordo com Dirksen et al. (1993). O diagnóstico presuntivo neste momento era de neoplasia a esclarecer. Optou-se pela excisão cirúrgica. $\mathrm{O}$ animal, após a tricotomia da tumoração e mais $20 \mathrm{~cm}$ ao redor, foi sedado com xilazina $(0,05 \mathrm{mg} /$ $\mathrm{kg}$ ), deitado sob cama de palha em decúbito lateral direito, recebeu infiltração de lidocaína $2 \%$ na base da tumoração e do tecido subcutâneo. Foram realizadas incisões oblíquas em forma de cunha, respeitando uma margem de segurança ampla que permitia a fácil oclusão da ferida cirúrgica; a massa foi extraída em sua junção com os tecidos adjacentes sem a retirada de qualquer tecido muscular. A sutura de aproximação foi realizada com pontos isolados simples e fio de náilon 2. Ao corte, a massa apresentou-se enegrecida e brilhante (Figura 2). O diagnóstico macroscópico após a excisão cirúrgica passou a ser de neoplasia melanocítica (melanoma ou melanocitoma).

O paciente permaneceu sob observação durante sete dias, sendo que após a retirada dos pontos a novilha recebeu alta. As grandes funções neste período permaneceram inalteradas. Uma amostra do tecido foi encaminhada em formalina
$10 \%$ ao exame histopatológico.

O tecido cutâneo apresentava degeneração epitelial severa com focos de hemorragia e microvesículas com conteúdo necrótico, presença de tecido neoplásico na derme, composto por estroma fibroso abundante e ninhos celulares de aspectos distintos; superficialmente composto por células predominantemente fusiformes, espaçadas e pouco coradas, e nas camadas mais profundas composto por células ovaladas a fusiformes, contendo forte pigmentação melânica. $\mathrm{O}$ tecido neoplásico apresentava moderado pleomorfismo, raras figuras de mitose e ausência de infiltrado inflamatório e áreas de necrose (Figura 3 e 4). O diagnóstico anátomopatológico consistiu de melanocitoma dérmico do tipo fibroso. Os melanocitomas são considerados como de comportamento benigno (SMITH; GOLDSCHMIDT; MCMANUS, 2002).

Figura 1: Localização de massa neoplásica em região de barbela de novilha de oito meses de idade da raça Jersey. Fazenda Rio Grande - PR, 2015.

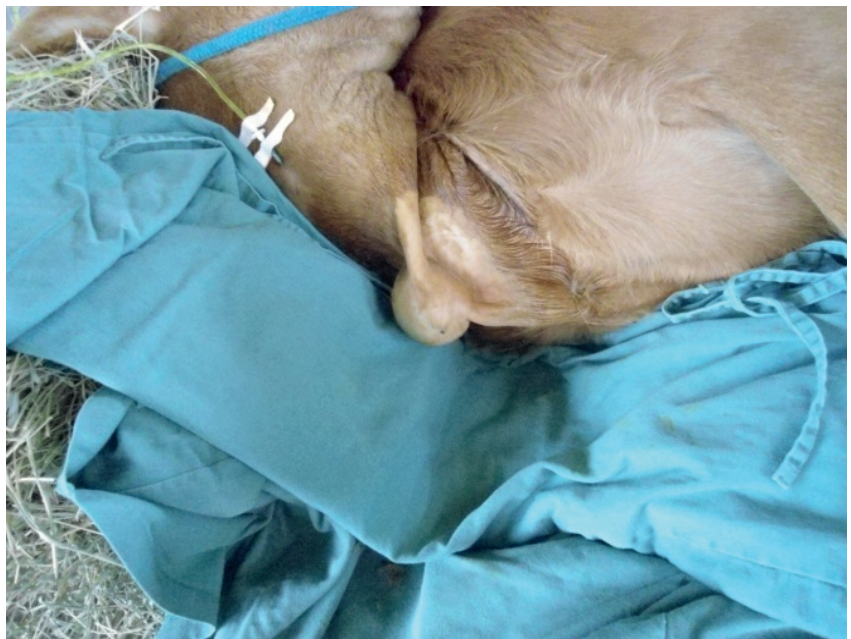

Fonte: Arquivo pessoal

Figura 2: Massa neoplásica melanocitica com aspecto negro brilhante retirado da região da barbela de novilha da raça Jersey com oito meses de idade. Fazenda Rio Grande - PR, 2015.

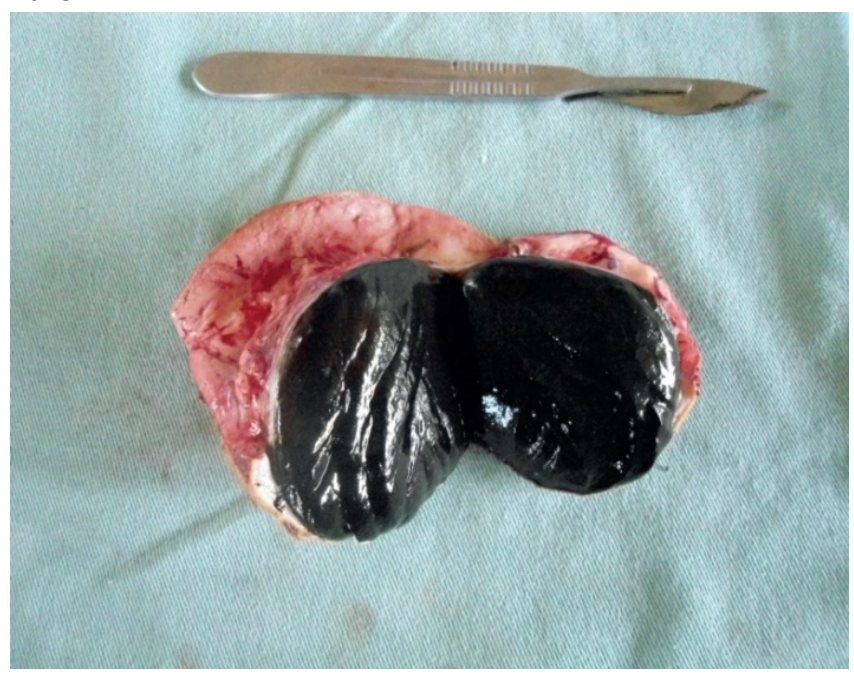

Fonte: arquivo pessoal 
Figura 3: Fotomicrografia de fragmento cutâneo de bovino apresentando tecido neoplásico composto por células fusiformes e abundante estroma fibroso (à esquerda na figura) e área composta por melanócitos ovalados a fusiformes apresentando pigmentação melânica (à direita) (coloração H\&E).

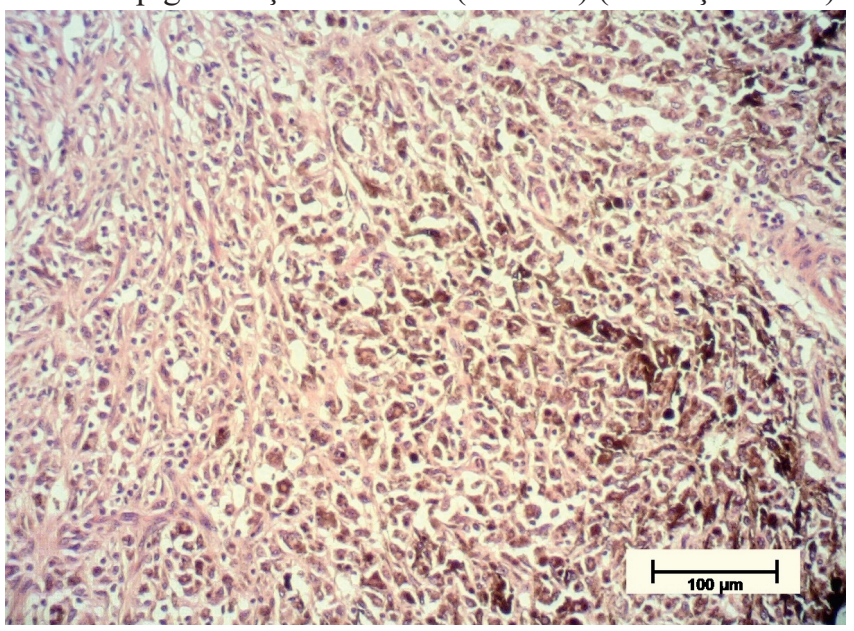

Figura 4: Área de melanocitoma bovino apresentando marcado aspecto fibroso e células fusiformes a ovaladas e moderadamente pigmentadas pela melanina (coloração de H\&E).

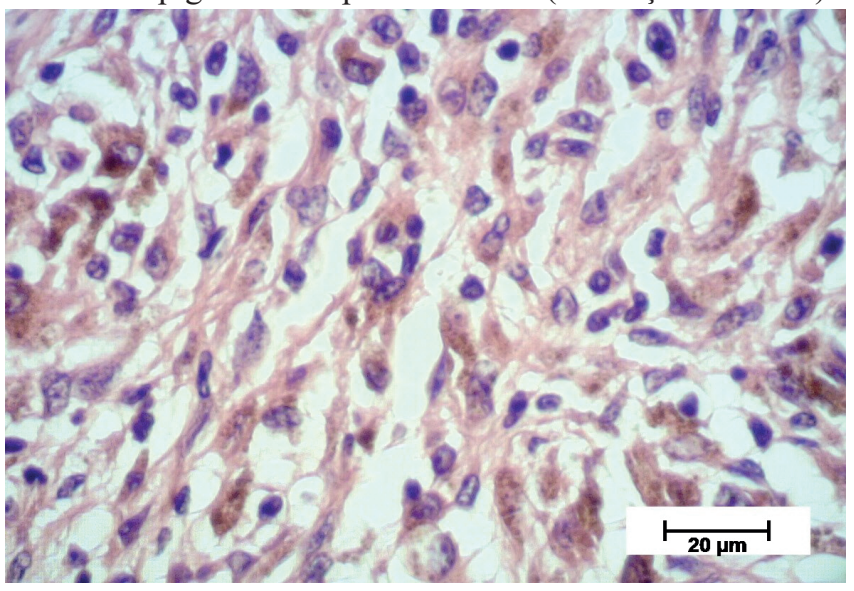

\section{Discussão e conclusão}

Aumentos de volume são achados comuns na inspeção de bovinos. $\mathrm{Na}$ grande maioria das vezes consistem de abscessos decorrentes de traumas físicos, vacinação inadequada e danos químicos aos tecidos (DIRKSEN, et al., 1993). É importante, no entanto, que o clínico buiatra tenha em mente possíveis diagnósticos diferenciais.

O diagnóstico clínico de neoplasia melanocítica foi corroborado pelos achados histológicos. A ausência de junção funcional à variação do conteúdo pigmentar e o desarranjo celular aparente o classificam como melanocitoma e o grande conteúdo fibroso encontrado o classificam como melanocitoma do tipo fibroso. De acordo com Cotchin (1960), em bovinos, as neoplasias melanocíticas geralmente são benignas ao contrário do que acontece em humanos e outras espécies animais. Dessa forma, podem crescer por longos períodos, tornando-se grandes massas sem, no entanto, afetar a saúde do animal. O caso relatado consiste de uma neoplasia melanocítica benigna que assim como descrito por Miller (1995), afeta animais jovens, podendo em alguns casos apresentar malignidade e metástases (ORTEGA-PACHECO et al., 1998; MESARIC et al., 2002; BRITO et al., 2009). Ao se observar a relação entre malignidade encontrada em espécies animais e humanos, encontra-se uma grande discrepância. Essa relação de quais os fatores que reduziriam a prevalência desta nos animais ainda não é bem clara (AGOSTINELLI et al., 2010). Foi demonstrado em experimentos com animais vivos e modelos celulares que amina oxidases do soro bovino tem a capacidade de converter a espermidina e a espermina em aldeídos e peróxidos, os quais limitam a proliferação celular, induzem a morte celular programada e podem reduzir o tamanho de tumores melanocíticos quando injetados diretamente na neoplasia (LINDSAY et al., 1999; BATESA, et al., 2008; AGOSTINELLI et al., 2010). A principal amina oxidase do soro bovino é a cobre $2,4,5$ trihidroxifenilaninoquinona, a qual está presente no soro de bovinos e suínos, mas não no soro de equinos e humanos (AGOSTINELLI et al., 2010). Os equinos podem ser mais susceptíveis a melanocitoma do que bovinos, bem como os melanomas aparecem com maior frequência nesta espécie, quanto aos suínos, ambas as manifestação podem ser comuns, porém estão confinadas a algumas raças e linhagens genéticas (DONALD., 2002; BABA; CÂTOI., 2007).

O tumor encontrado tem características físicas e histopatológicas semelhantes às encontradas por Babic et al. (2009), que descreveram uma massa ovoide medindo cerca de $7 \times 8 \mathrm{~cm}$ com aspecto preto ao corte em membro posterior de bezerro de três meses de idade. O mesmo foi descrito por Sharma et al. (2010), em uma vaca de cinco anos de idade que apresentava o tumor na região do flanco esquerdo e Fazili et al. (2011) descreve a localização logo cranial ao úbere.

Assim como o resultado obtido no exame histopatológico da neoplasia, a característica fundamental dos melanomas e melanocitomas é o pleomorfismo e variação dos padrões de crescimento e grau de pigmentação das células neoplásicas. Na maioria dos casos, as grandes quantidades de melanina presentes no citoplasma das células tumorais não deixam dúvida com relação ao diagnóstico (BABA; CÂTOI, 2007).

Fazili et al. (2011) relatam que o procedimento de retirada da massa tumoral é relativamente simples e até o momento não foi registrada recidiva, assim como em outras exéreses totais.

\section{Referências}

AGOSTINELLI, E. et al. Potential anticancer application of polyamine oxidation products formed by amine oxidase: a new therapeutic approach. Amino Acids, v. 38, n. 2, p. 353368, 2010.

\section{BABA, A. I.; CÂTOI, C. Comparative oncology. Bucharest: The Publishing House of the Romanian Academy, 2007.}

BABIC, T. et al. Congenital malanoma in a 3-month old bull calf. Veterinary Archives, v. 79, p. 315-320, 2009.

BATESA, D. A. et al. Mechanism of cell death induced by spermine and amine oxidase in mouse melanoma cells. Journal of oncology, v. 32, n. 1, p. 79-88, 2008. 
BRITO, M. F. et al. Melanoma oral metastático em uma vaca. Ciência Rural, v. 39, n. 4, p. 1248-1252, 2009.

COTCHIN, B. Tumors of farm animals. Veterinary

Record, v. 72, p. 816-822, 1960.

DIRKSEN, G.; GRÜNDER, H. D.; STÖBER, M. (ED.)

Rosenberger: exame clínico dos bovinos. 3. ed. Rio de Janeiro: Guanabara Koogan, 1993.

FAZILI, M. R. et al. Cutaneous melanocytoma in a crossbred Jersey cow. Indian Journal of Veterinary Surgery, v. 32, p. 73, 2011.

GARNA-AVIÑA, A.; VALLI, V. E.; LUMSDEN, J. H. Cutaneous melanomas in domestic animals. Journal of Cutaneous Pathology, v. 8, p. 3-24, 1981.

LINDSAY, G. S.; WALLACE, H. M. Changes inpolyamine catabolism in HL-60 human promyelogenous leukaemic cells in response to etoposide-induced apoptosis.

Biochemical Journal, v. 337,p. 83-87, 1999.

MESARIC, M.; ZADNIK, T.; MANCA, C. Malignant melanoma in a cow. Acta Veterinaria (Beograd), v. 52, n. 1, p. 59-64, 2002.

MILLER, M. A. et al. Cutaneous melanocytomas in 10 young cattle. Veterinary Pathology, v. 32, n. 5, p. 479-484, 1995.

ORTEGA-PACHECO, A.; MIRANDA-SOBERANIS, J.

Tumor melanocitico maligno em un bovino: reporte de caso.

Revista Biomédica, v. 9, p. 48-49, 1998.

PARKIN, D. M. et al. Global Cancer Statistics, 2002. CA

Cancer Journal for Clinicians, v. 55, p. 74-108, 2005.

SHARMA, S.; CHAUDHARY, R. N.; SINGH, K.

Melanoma in a hariana cow. Haryana Veterinary, v. 49, p. $78,2010$.

SIVADAS, C. G. et al. Congenital melanoma in a calf. A review and case report. British Veteterinary Journal, v. 127 , p. $289-293,1971$

SMITH, S. H.; GOLDSCHMIDT, M. H.; MCMANUS, P. M. A comparative review of melanocytic neoplasms. Veterinary Pathology, v. 39, p. 651-678, 2002.

TEIXEIRA, A. B. Incidência de melanomas em animais domésticos, 2004. Dissertação (Monografia) - Curso de Medicina Veterinária, Faculdade de Ciências Agrárias da Universidade de Marília, Marília-SP.

YERUHAN, I.; PERL, S.; ORGAD, U. Congenital skin neoplasia in cattle. Veterinary Dermatology, v. 10, p. 149156, 1999.
Recebido em: 19.04.2015

Aceito em: 17.03.2016 